\title{
The Effect of Temperature Increases on Brain Tissue Oxygen Tension in Patients with Traumatic Brain Injury: A Collaborative European NeuroTrauma Effectiveness Research in Traumatic Brain Injury Substudy
}

\begin{abstract}
Verena Rass, MD, ${ }^{1}$ Lukas Huber, MSc, ${ }^{2}$ Bogdan-Andrei lanosi, MD,,2 Mario Kofler, MD, ${ }^{1}$ Anna Lindner, MD, Edoardo Picetti, MD, ${ }^{3}$ Fabrizio Ortolano, MD, ${ }^{4}$ Ronny Beer, MD, ${ }^{1}$ Sandra Rossi, MD, ${ }^{3}$ Peter Smielewski, PhD, Nino Stocchetti, MD, ${ }^{4,6}$ and Raimund Helbok MD ${ }^{1}$; and CENTER-TBI HR ICU Investigators and Participants*
\end{abstract}

Fever may aggravate secondary brain injury after traumatic brain injury (TBI). The aim of this study was to identify episodes of temperature increases through visual plot analysis and algorithm supported detection, and to describe associated patterns of changes in on brain tissue oxygen tension $\left(\mathrm{P}_{\mathrm{bt}} \mathrm{O}_{2}\right)$. Data derive from the highresolution cohort of the multicenter prospective Collaborative European NeuroTrauma Effectiveness Research in TBI (CENTER-TBI) study. Temperature increases $\left(\geq 0.5^{\circ} \mathrm{C}\right)$ were visually identified in 33 patients within the first 11 days of monitoring. Generalized estimating equations were used to detect significant changes of systemic and neuromonitoring parameters from baseline to the highest temperature. Patients were median 50 (interquartile range [IQR], 35-62) years old, and presented with a Glasgow Coma Scale (GCS) of 8 (IQR, 410). In 202 episodes of temperature increases, mean temperature rose by $1.0^{\circ} \mathrm{C} \pm 0.5^{\circ} \mathrm{C}$ within 4 hours. Overall, $\mathrm{P}_{\mathrm{bt}} \mathrm{O}_{2}$ slightly increased $\left(\Delta \mathrm{P}_{\mathrm{bt}} \mathrm{O}_{2}=0.9 \pm 6.1 \mathrm{mmHg}, p=0.022\right)$ during temperature increases. $\mathrm{P}_{\mathrm{bt}} \mathrm{O}_{2}$ increased in $35 \%(p<0.001)$, was stable in $49 \%(p=0.852)$, and decreased in $16 \%(p<0.001)$ of episodes. During episodes of temperature increases and simultaneous drops in $\mathrm{P}_{\mathrm{bt}} \mathrm{O}_{2}$, cerebral perfusion pressure (CPP) decreased $(\Delta C P P$ $-6.3 \pm 11.5 \mathrm{mmHg} ; p<0.001)$. Brain tissue hypoxia $\left(\mathrm{P}_{\mathrm{bt}} \mathrm{O}_{2}<20 \mathrm{mmHg}\right)$ developed during $27 / 164$ (17\%) episodes of effervescences, in the remaining 38/202 episodes baseline $\mathrm{P}_{\mathrm{bt}} \mathrm{O}_{2}$ was already $<20 \mathrm{mmHg}$. Comparable results were found when using algorithm-supported detection of temperature increases. In conclusion, during effervescences, $\mathrm{P}_{\mathrm{bt}} \mathrm{O}_{2}$ was mostly stable or slightly increased. A decrease of $\mathrm{P}_{\mathrm{bt}} \mathrm{O}_{2}$ was observed in every sixth episode, where it was associated with a decrease in CPP. Our data highlight the need for special attention to CPP monitoring and maintenance during episodes of fever.

Keywords: traumatic brain injury, temperature increases, brain tissue oxygen tension, critical care, CENTER-TBI

\section{Introduction}

$\mathbf{S}$ EVERE TRAUMATIC BRAIN injury (TBI) is a devastating disease that is still associated with a considerable rate of morbidity and mortality despite tremendous improvements in the critical care management (Steyerberg et al., 2019). Sys- temic complications, including fever frequently occur in the early phase after trauma and likely exacerbate secondary brain injury (Walter et al., 2016). Up to $50 \%$ of patients following acute brain injury develop fever within the hospitalization time (Kilpatrick et al., 2000). While deleterious effects of fever and their association with unfavorable outcomes

\footnotetext{
${ }^{1}$ Department of Neurology, Medical University of Innsbruck, Innsbruck, Austria.

${ }^{2}$ Institute of Medical Informatics, UMIT: University for Health Sciences, Medical Informatics and Technology, Hall, Austria.

${ }^{3}$ Department of Anesthesia and Intensive Care, Parma University Hospital, Parma, Italy.

${ }^{4}$ Neuroscience Intensive Care Unit, Department of Anesthesia and Critical Care, Fondazione IRCCS Cà Granda Ospedale Maggiore Policlinico, Milan, Italy.

${ }^{5}$ Brain Physics Laboratory, Division of Neurosurgery, Addenbrooke's Hospital, Cambridge University Hospital NHS Foundation Trust, Cambridge, United Kingdom.

${ }^{6}$ Department of Pathophysiology and Transplants, University of Milan, Milan, Italy.

*For members, see Acknowledgments section.

This multicenter study was performed at 21 European sites.
} 
are well described (Greer et al., 2008), underlying pathophysiologic mechanisms are still not fully elucidated. Fever is associated with multiple systemic and cerebral changes, such as an increased metabolic demand (Busija et al., 1988; Holtzclaw, 1992), increased endogenous stress levels, alterations in blood pressure levels (Walter et al., 2016), increases in cardiac output and heart rate (HR) (Bain et al., 2014), hyperventilation, the synaptic release of excitatory amino acids (Stocchetti et al., 2005), elevated intracerebral pressure (ICP) levels (Rossi et al., 2001; Stocchetti et al., 2005; Nyholm et al., 2017), ischemic cortical depolarizations, and blood-brain barrier breakdown (Wang et al., 2014).

Assessing brain tissue oxygen tension $\left(\mathrm{P}_{\mathrm{bt}} \mathrm{O}_{2}\right)$ along with other hemodynamically relevant factors during episodes of temperature increases may provide insight into changes in oxygen supply and consumption (Le Roux et al., 2014). Most data investigating the influence of different temperature levels on cerebral oxygenation are derived from animal studies or from human studies in which mostly patients with hypothermia were studied (Tokutomi et al., 2003; Zhi et al., 2003; Flynn et al., 2015). Some studies in humans (Stocchetti et al., 2005; Spiotta et al., 2008; Nyholm et al., 2017) assessed the association between $\mathrm{P}_{b t} \mathrm{O}_{2}$ and fever and report no significant decrease of $\mathrm{P}_{b t} \mathrm{O}_{2}$ levels during fever. However, little is known how changes in body temperature (in particular increases) influence brain tissue oxygen tension, irrespective of the absolute temperature.

In this study, we aimed to quantify changes in $\mathrm{P}_{\mathrm{bt}} \mathrm{O}_{2}$ during temperature increases in severe TBI patients and to explore simultaneous changes of hemodynamic parameters and the cerebral autoregulatory state (cerebral perfusion pressure, CPP; mean arterial pressure, MAP; HR; pressure reactivity index, PRx; oxygen reactivity index, ORx). Moreover, we intended to compare episodes of temperature increases identified through visual plot analysis and by algorithmsupported detection. Our primary hypothesis was that the rise in temperature carries the risk of brain tissue hypoxia, explained by hemodynamic changes.

\section{Methods}

\section{Study population}

In the intensive care unit (ICU) stratum of the Collaborative European NeuroTrauma Effectiveness Research in TBI (CENTER-TBI, registered at clinicaltrials.gov NCT 02210221) core study, high-resolution data were collected in a subset of 277 patients admitted to 21 European centers. Of these, 102 patients were selected with reliable continuous temperature recordings. Thirty-three patients had additional monitoring of $\mathrm{P}_{\mathrm{bt}} \mathrm{O}_{2}$ and were included in the final analysis. Patients were recruited from January 2015 until December 2017. These patients were admitted to the ICU following a moderate (initial Glasgow Coma Scale [GCS] 9-12) or severe $($ GCS $\leq 8)$ TBI. Few patients initially suffered from mild-tomoderate TBI but deteriorated early prompting ICU admission. Insertion of ICP probes confirmed to BTF (Brain Trauma Foundation) guidelines in all patients (Carney et al., 2017). Therefore, a multimodal neuromonitoring bundle was only initiated in patients with severe TBI on admission or in those with neurologic deterioration. Data collection in the CENTERTBI study adhered to ethical standards and the study was approved by the Medical Ethics Committees of all participating centers. Informed consent was obtained in accordance with local regulations (Steyerberg et al., 2019). The Austrian Ethics approval is given as an example (Medical University of Innsbruck, AN2014-0336 343/4.22). The list of ethics committee approvals of participating sites is online.*

\section{Data collection and preprocessing}

All demographic variables were prospectively collected and entered in an electronic case report form (Quesgen, Inc., Burlingame, CA) after interpretation by physicians and/or research assistants. Clinical data were collected on a daily basis: at ICU admission, during ICU stay (days 1-7, 10, 14, $21,28)$, and at ICU discharge. Demographic variables were derived from the Core Registry (V2.0).

In the high-resolution CENTER-TBI substudy, highfrequency digital signals of vital parameters were recorded during the ICU stay. Arterial blood pressure (ABP) was most often measured through either radial or femoral arterial lines. ICP was obtained using an intraparenchymal probe (Codman ICP MicroSensor; Codman \& Shurtleff, Inc., Raynham, MA), parenchymal fiberoptic pressure sensor (Camino ICP Monitor; Integra Life Sciences, Plainsboro, NJ) or, rarely, external ventricular drain. Signal processing was done using the ICM+ software (Cambridge Enterprise Ltd., Cambridge, United Kingdom).

Signal artifacts were removed partially through visual inspection and also using automated algorithmic methods. For ABP $(0-300 \mathrm{mmHg})$ and ICP $(0-100 \mathrm{mmHg})$ a primary filter was used. ABP data were removed if the pulsatility of $\mathrm{ABP}\left(\mathrm{ABP}_{\max }-\mathrm{ABP}_{\min }\right)$ within 1.5 seconds was $<20$ or $>200 \mathrm{mmHg}$. HR was calculated with use of the fundamental frequency function within 10 seconds on the ABP signal (using the Fourier fast transformation) with a lower and upper limit of $40 / \mathrm{min}$ and $180 / \mathrm{min} . \mathrm{P}_{\mathrm{bt}} \mathrm{O}_{2}$ levels $>60$ or $<0 \mathrm{mmHg}$ and temperature levels $>45^{\circ} \mathrm{C}$ or $<30^{\circ} \mathrm{C}$ were considered implausible and therefore deleted. CPP was calculated as follows: MAP ICP. Autoregulatory indices were calculated as previously described: PRx was calculated as a moving Pearson correlation between 30 consecutive 10-second averages of ICP and MAP, resulting in a moving 5-minute time window, increasing in 10-second steps (Czosnyka et al., 1997). Similarly, ORx was calculated as a moving Pearson correlation between 120 consecutive 30-second averages of $\mathrm{P}_{\mathrm{bt}} \mathrm{O}_{2}$ and CPP, resulting in a 1-hour moving time window (Jaeger et al., 2006).

High-frequency data (MAP; HR; fraction of inspired oxygen, $\mathrm{FiO}_{2}$; temperature; ICP; $\mathrm{CPP} ; \mathrm{P}_{\mathrm{bt}} \mathrm{O}_{2}$; ORx; $\mathrm{PRx}$ ) were averaged over 10 minutes.

Brain tissue hypoxia was defined as $\mathrm{P}_{\mathrm{bt}} \mathrm{O}_{2}<20 \mathrm{mmHg}$, since this is the threshold prompting interventions according to current practices (Le Roux et al., 2014).

\section{Fever definitions}

Temperature was either measured intracranially $(N=16$, $49 \%)$, external-axillary $(N=2,6 \%)$, by a bladder $(N=11$, $33 \%)$, or tympanic temperature sensor $(N=2,6 \%)$. In two patients $(6 \%)$, temperature was derived from a mixed source. Fever was defined as temperature levels above $38.3^{\circ} \mathrm{C}$, irrespective of the measurement site. Temperature levels were

*CENTER-TBI. Ethical approval. https://www.center-tbi.eu/project/ ethical-approval 
Table 1. Demographics of 33 Patients

\begin{tabular}{|c|c|}
\hline & $\mathrm{N}(\%)$ or median $(I Q R)$ \\
\hline \multicolumn{2}{|l|}{ Clinical characteristics on admission } \\
\hline Age & $50(34-66)$ \\
\hline Female sex & $6(18)$ \\
\hline Marshall Score & $3(2-5)$ \\
\hline GCS & $8(4-10)$ \\
\hline GCS motor & $3(1-5)$ \\
\hline \multicolumn{2}{|l|}{ Pupil reactivity } \\
\hline Both reactive & $28(85)$ \\
\hline Both unreactive & $2(6)$ \\
\hline One unreactive & $3(9)$ \\
\hline Preinjury ASA score & $2(1-3)$ \\
\hline Injury severity score & $27(25-41)$ \\
\hline \multicolumn{2}{|l|}{ Hospital complications } \\
\hline Cranial surgery & $18(55)$ \\
\hline Meningitis & $0(0)$ \\
\hline Ventilator-associated pneumonia & $18(55)$ \\
\hline Bloodstream infection & $4(12)$ \\
\hline Urinary tract infection & $8(24)$ \\
\hline Neuroworsening during ICU-stay & $18(55)$ \\
\hline Progression on CT-scan & $12(36)$ \\
\hline \multicolumn{2}{|l|}{ Outcomes } \\
\hline \multicolumn{2}{|l|}{ GOSE at 6 months } \\
\hline 1 & $10(30)$ \\
\hline 2 & $2(18)$ \\
\hline 3 & $2(6)$ \\
\hline 4 & $5(15)$ \\
\hline 5 & $6(18)$ \\
\hline 6 & $2(6)$ \\
\hline 7 & $2(6)$ \\
\hline
\end{tabular}

ASA, American Society of Anesthesiologists; CT, computed tomography; GCS, Glasgow Coma Scale; GOSE, Extended Glasgow Outcome Scale; ICU, intensive care unit; IQR, interquartile range. further categorized using the following definitions: subfebrile $37.5-38.3^{\circ} \mathrm{C}$, normothermia $36.5-37.5^{\circ} \mathrm{C}$, low body temperature $35-36.5^{\circ} \mathrm{C}$, and hypothermia $32-35^{\circ} \mathrm{C}$.

\section{Data analysis}

There was no significant difference in temperature in the subset of patients with $\mathrm{P}_{\mathrm{bt}} \mathrm{O}_{2}$ probes compared with all patients with temperature data, both following similar distributions. To minimize bias from a few longer monitoring sessions, periods of duration greater than 11 days were cropped at 11 days for the purpose of analysis. A clinically relevant episode of temperature increase (effervescence) was defined as an increase by $\geq 0.5^{\circ} \mathrm{C}$ irrespective of a time limit or measurement site. These episodes were manually identified by data visualization. Episodes with changes in $\mathrm{FiO}_{2}$ during temperature increases were excluded $(N=9)$. Changes in vital and neuromonitoring parameters were expressed by calculating the difference between the baseline (defined by the lowest temperature level of each episode) and the highest temperature within each episode of temperature increase and reported as mean \pm standard deviation of the difference. $\mathrm{P}_{b t} \mathrm{O}_{2}$ changes were further categorized into decreasing, increasing, or stable by visual $\mathrm{P}_{b t} \mathrm{O}_{2}$ curve inspection. Based on the characteristics of the temperature curves of manually detected temperature increases, an algorithmsupported detection of temperature increases was developed with two prerequisites: (1) baseline temperature $>35^{\circ} \mathrm{C}$ and (2) velocity of temperature increase $>0.0167^{\circ} \mathrm{C} / 10 \mathrm{~min}$ utes $=0.1^{\circ} \mathrm{C} / \mathrm{h}$ based on the lower quartile of manual detection. Applying this algorithm, additional characteristics of the assisted episode algorithm have been evaluated with different parameters: (1) $\geq 0.5^{\circ} \mathrm{C}$ increase, (2) temperature

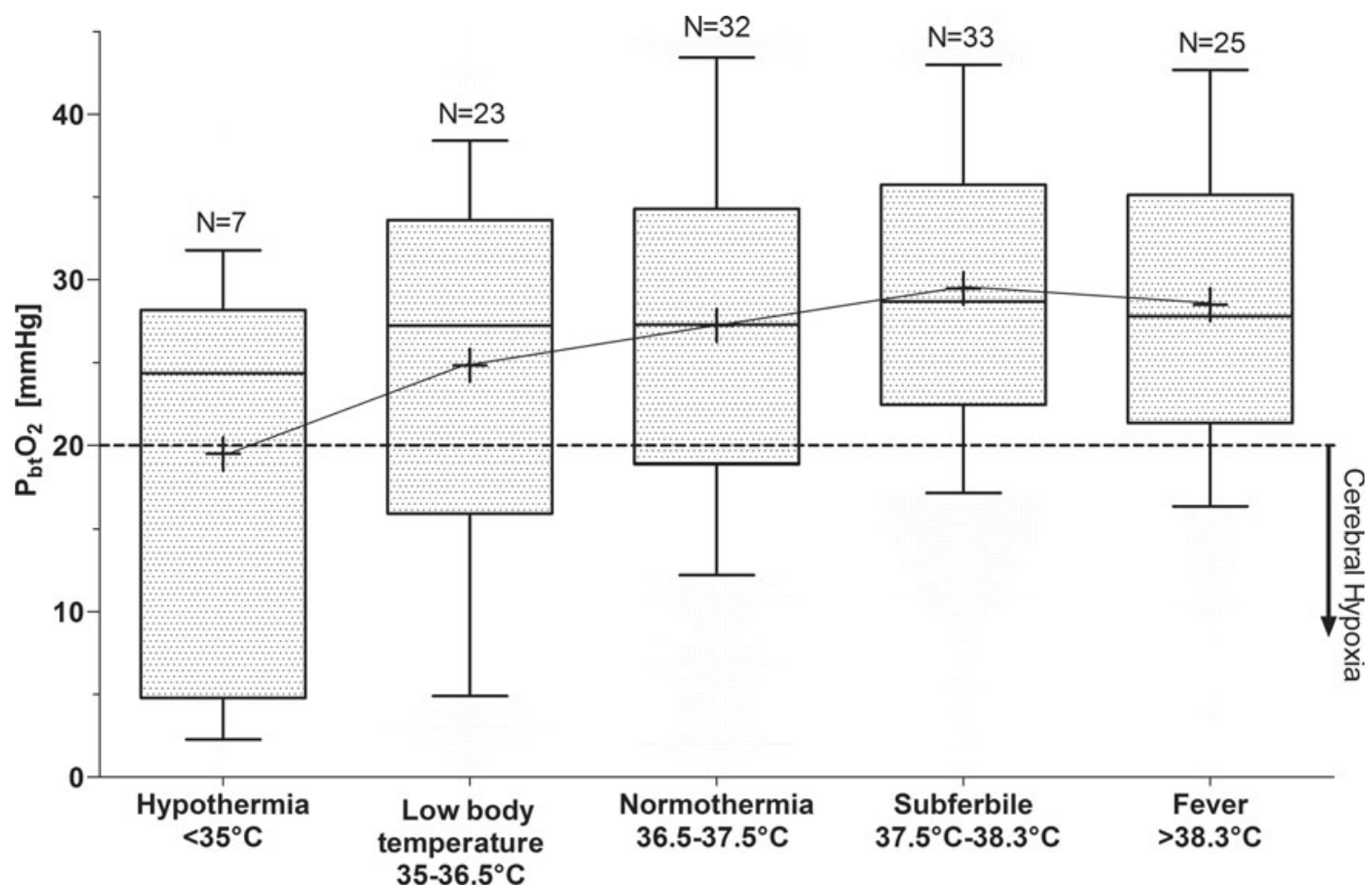

FIG. 1. Mean $\mathrm{P}_{b t} \mathrm{O}_{2}$ values were significantly higher at higher temperature levels $(p<0.001)$. $\mathrm{P}_{b t} \mathrm{O}_{2}$, brain tissue oxygen tension. 
Table 2. Changes in Brain Tissue Oxygen Tension and Hemodynamic Variables During Temperature Increases Splitting at Different Patterns of Brain Tissue Oxygen Tension Changes

\begin{tabular}{|c|c|c|c|c|c|c|c|c|c|c|c|c|}
\hline & $P_{b t} O_{2} b l$ & $P_{b t} O_{2}$ peak & $\Delta P_{b t} O_{2}$ & $T b l$ & T peak & $\Delta T$ & $C P P b l$ & CPP peak & $\triangle C P P$ & $M A P b l$ & MAP peak & $\triangle M A P$ \\
\hline \multirow[t]{2}{*}{$N=202$} & $27.7 \pm 10.1$ & $28.6 \pm 10.2$ & & & & & 80.1 & & & & & \\
\hline & $\mathbf{O R}=$ & $\%-\mathrm{CI}=1.01-1$ & 0.022 & & & & $\mathbf{O R}=$ & & $=$ & & & \\
\hline \multirow{5}{*}{$\begin{array}{l}\mathrm{P}_{\mathrm{bt}} \mathrm{O}_{2} \\
\quad \text { increase } \\
N=71 \\
\mathrm{P}_{\mathrm{bt}} \mathrm{O}_{2} \text { stable } \\
N=98 \\
\mathrm{P}_{\mathrm{bt}} \mathrm{O}_{2} \\
\quad \text { decrease }\end{array}$} & $26.6 \pm 9.8$ & $32.3 \pm 8.8$ & $5.7 \pm 4.4$ & $36.9 \pm 0.8$ & $37.9 \pm 0.8$ & $1.0 \pm 0.4$ & 16.8 & $77.4 \pm 16.1$ & $=13.6$ & 17.3 & 16.8 & 9.8 \\
\hline & $\mathrm{OR}=1.22$ & $\%-\mathrm{CI}=$ & $.27 ; p<0.001$ & & & & $\mathbf{O R}=$ & $7-\mathbf{C I}-077$ & $.998 p=0.046$ & & $p=0.106$ & \\
\hline & $28.2 \pm 10.6$ & $\begin{array}{l}27.5 \pm 10.5 \\
p=0.852\end{array}$ & $0.6 \pm 5.3$ & $37.0 \pm 0.8$ & $38.0 \pm 0.6$ & $1.0 \pm 0.5$ & $\begin{array}{c}81.0 \pm 17.2 \\
\text { OR }=\mathbf{0 . 9 1 ; 9}\end{array}$ & $\begin{array}{c}76.3 \pm 14.6 \\
\%-\mathbf{C I}=\mathbf{0 . 8 3}-\end{array}$ & $\begin{array}{c}-4.7 \pm 12.2 \\
.99 ; p=\mathbf{0 . 0 2 8}\end{array}$ & $\begin{array}{c}96.4 \pm 17.8 \\
\mathbf{O R}=\mathbf{0 . 9 2} ; \mathbf{9 5}\end{array}$ & $\begin{array}{r}93.7 \pm 16.9 \\
\%-C I=0.86\end{array}$ & $\begin{aligned}-2.7 & \pm 9.9 \\
-\mathbf{0 . 9 9} ; \boldsymbol{p} & =\mathbf{0 . 0 2 2}\end{aligned}$ \\
\hline & $28.7 \pm 9.4$ & $23.6 \pm 9.7$ & $-5.1 \pm 3.5$ & $36.7 \pm 1.0$ & $37.7 \pm 0.8$ & $1.0 \pm 0.6$ & $78.5 \pm 15.7$ & $72.2 \pm 13.1$ & $-6.3 \pm 11.5$ & $92.2 \pm 17.8$ & $86.1 \pm 17.4$ & -5.7 \\
\hline & \multicolumn{6}{|c|}{$\mathrm{OR}=0.78 ; 95 \%-\mathrm{CI}=0.72-0.85 ; p<0.001$} & \multicolumn{3}{|c|}{$\mathrm{OR}=0.72 ; 95 \%-\mathrm{CI}=0.61-0.83 ; p<0.001$} & \multicolumn{3}{|c|}{$\mathrm{OR}=0.72 ; 95 \%-\mathrm{CI}=0.61-0.86 ; p<0.001$} \\
\hline
\end{tabular}

Hemodynamic and neuromonitoring parameters are expressed as mean \pm standard deviation at baseline and highest temperature within each episode of temperature increase. Using generalized estimating equations, the significance of changes of each variable $(\Delta)$ within temperature increases was tested in univariate analysis. Significant changes $(p<0.05)$ are bold.

bl, baseline; CI, confidence interval; CPP, cerebral perfusion pressure; HR, heart rate; ICP, intracerebral pressure; MAP, mean arterial pressure; OR, odds ratio; ORx, oxygen reactivity index; $\mathrm{P}_{\mathrm{bt}} \mathrm{O}_{2}$, brain tissue oxygen tension; PRx, pressure reactivity index; $\mathrm{T}$, temperature.

increases lasting $>1$ hour, and (3) temperature increases lasting $>20$ minutes.

The values were automatically processed for sets of given parameters. For imputation, the function "last observation carry forward" was used from the zoo package. This function replaces each missing value with the most recent nonmissing value before it (Zeileis and Grothendieck, 2005). Imputations were made in (1) $9 / 71$ episodes of $\geq 0.5^{\circ} \mathrm{C}$ increase, (2) 54/ 183 episodes of temperature increases lasting $>1$ hour, and (3) $171 / 532$ episodes of temperature increases lasting $>20$ minutes.

\section{Statistics}

Statistical analysis of anonymized patient data was performed by L.H. who was not involved in data collection and who was blinded to the clinical course of all patients. For creation of the summary tables of each episode, the summary tools package was used (Dominic Comtois, 2019; summarytools: Tools to Quickly and Neatly Summarize Data, R package version 0.9.4).

$\mathrm{P}_{\mathrm{bt}} \mathrm{O}_{2}$ changes $\left(\Delta \mathrm{P}_{\mathrm{bt}} \mathrm{O}_{2}\right)$, as well as changes of other vital and neuromonitoring parameters within temperature increases were tested in univariate analysis using generalized estimated equations with an autoregressive matrix to account for repeated measurements. Vital or neuromonitoring parameters at baseline or highest temperature points were compared across different $\mathrm{P}_{\mathrm{bt}} \mathrm{O}_{2}$ characteristics using the $t$-test or Mann-Whitney U Test, as appropriate.

The analysis and visualizations were conducted using $\mathrm{R}$ version 3.6.0 (2019-04-26) and SPSS (version 24.0; IBM SPSS Statistics, Armonk, NY). The analysis was conducted under the consolidation of RMarkdown notebooks, which allowed the analysis code and representation in one document. RMarkdown allows a notebook interface to the analysis, which was especially useful with regard to changes of the data, layout refinement, plots, and discussion of the authors. Statistical significance was attributed to a $p$-value $<0.05$.

\section{Results}

Of 102 patients prospectively included in the highresolution ICU cohort, 33 patients met the inclusion criteria for the current analysis. Baseline characteristics were not different between the study population and excluded patients (age $p=0.202$, sex $p=1.000$, GCS at baseline $p=0.114$, GCS motor at baseline $p=0.377)$. Detailed information on baseline characteristics, hospital complications, and outcomes of 33 patients is given in Table 1 . In total, 3587 neuromonitoring hours (median per patient 86; interquartile range [IQR] 61159 hours) with simultaneous $\mathrm{P}_{\mathrm{bt}} \mathrm{O}_{2}$ and temperature measurements during the first 11 days of ICU stay were analyzed. Episodes of fever within the study time occurred in most patients $(26 / 33,79 \%)$ and were observed during $13 \%$ of monitoring time (471 hours). During episodes of fever, brain tissue hypoxia $\left(\mathrm{P}_{\mathrm{bt}} \mathrm{O}_{2}<20 \mathrm{mmHg}\right)$ was found in $20 \%$ of measurements, which was comparable to the overall incidence of brain tissue hypoxia $(25 \%)$ over the whole study period. Mean $\mathrm{P}_{\mathrm{bt}} \mathrm{O}_{2}$ values were significantly higher at higher temperature levels (Kruskal-Wallis: $p<0.001$ ) (Fig. 1). In this line, there was a weak-positive correlation between higher temperature and higher $\mathrm{P}_{\mathrm{bt}} \mathrm{O}_{2}$ levels (rho=0.11; $p<0.01)$.

\section{Changes in $\mathrm{P}_{b t} \mathrm{O}_{2}$ and hemodynamic variables during temperature increases}

Two hundred two episodes of clinically significant temperature increases $\left(\geq 0.5^{\circ} \mathrm{C}\right)$ were visually identified (Supplementary Fig. S1). Mean temperature increase was $1.0^{\circ} \mathrm{C} \pm 0.5^{\circ} \mathrm{C}$ from $36.9^{\circ} \mathrm{C} \pm 0.8^{\circ} \mathrm{C}$ to $37.9^{\circ} \mathrm{C} \pm 0.7^{\circ} \mathrm{C}$ within 4 hours resulting in a mean slope of $0.33 \pm 0.34^{\circ} \mathrm{C} / \mathrm{h}$ (median $\left.0.22^{\circ} \mathrm{C} / \mathrm{h}, \mathrm{IQR} 0.16-0.35\right)$. Overall, $\mathrm{P}_{\mathrm{bt}} \mathrm{O}_{2}$ slightly increased by $0.9 \pm 6.1 \mathrm{mmHg}(p=0.022)$ from baseline to temperature peak. Neither a higher $\Delta$ temperature nor higher rate of the temperature increase influenced the change of $\Delta \mathrm{P}_{\mathrm{bt}} \mathrm{O}_{2}$ (Generalized linear model: $p=0.179 ; p=0.160$ ). Importantly, mean $\mathrm{P}_{\mathrm{bt}} \mathrm{O}_{2}$ values were within normal range $(\geq 20 \mathrm{mmHg}$ ) both at baseline and at the highest temperature of each episode, as shown in Table 2. Manual classification revealed clinically important patterns of $\mathrm{P}_{\mathrm{bt}} \mathrm{O}_{2}$ changes within periods of temperature increase. $\mathrm{P}_{\mathrm{bt}} \mathrm{O}_{2}$ increased in $35 \%\left(\Delta \mathrm{P}_{\mathrm{bt}} \mathrm{O}_{2}=+5.7 \pm 4.4 \mathrm{mmHg}, p<0.001\right)$, did not change in $49 \%\left(\Delta \mathrm{P}_{\mathrm{bt}} \mathrm{O}_{2}=-0.6 \pm 5.3 \mathrm{mmHg}, p=0.852\right)$, and decreased in $16 \%\left(\Delta \mathrm{P}_{\mathrm{bt}} \mathrm{O}_{2}=-5.1 \pm 3.5 \mathrm{mmHg}, p<0.001\right)$ (Fig. 2) of episodes. During episodes with drops in $\mathrm{P}_{\mathrm{bt}} \mathrm{O}_{2}$, brain tissue hypoxia was either evident at baseline $(3 / 33,9 \%)$ or developed during effervescence $(30 \%, 9 / 30)$. In the overall cohort, baseline brain tissue hypoxia was found in 38/202 (19\%) episodes. Of the remaining 164 episodes of effervescence 
TABle 2. (CONTINUED)

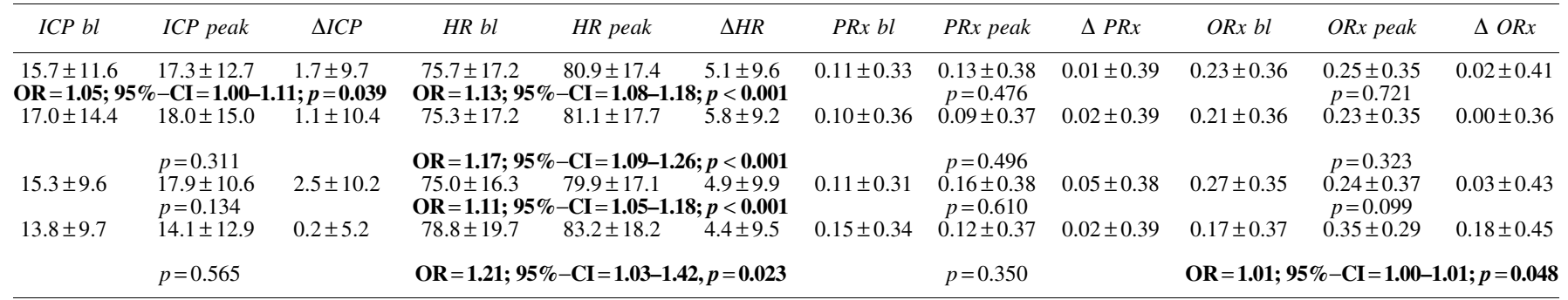

where $\mathrm{P}_{b t} \mathrm{O}_{2 \text { baseline }}$ was $\geq 20 \mathrm{mmHg}$, brain tissue hypoxia developed in 27/164 (17\%) episodes. Persistent brain tissue hypoxia (not resolving until the peak of temperature increase) was seen in $15 / 164(9 \%)$ episodes of temperature increases. Importantly, different $\mathrm{P}_{b t} \mathrm{O}_{2}$ patterns were observed within individual patients.

Descriptive analysis of important covariates reflecting the hemodynamic situation and autoregulatory state during temperature increases demonstrated an increase in HR $(p<0.001)$, irrespective of $\mathrm{P}_{\mathrm{bt}} \mathrm{O}_{2}$ characteristics. During temperature increases with drops in $\mathrm{P}_{\mathrm{bt}} \mathrm{O}_{2}$, a decrease in CPP was more pronounced as compared with episodes when $\mathrm{P}_{\mathrm{bt}} \mathrm{O}_{2}$ increased. During CPP decreases, drops in MAP $(p<0.001)$, but not increases in ICP $(p=0.565)$, were observed. Details are given in Table 2.
The autoregulatory status as assessed with the PRx was not different at baseline $(p=0.564)$ or peak temperature $(p=0.826)$ comparing episodes when $\mathrm{P}_{\mathrm{bt}} \mathrm{O}_{2}$ decreased or increased and PRx did not change during effervescences (Table 2). In this line, the percentage of impaired autoregulation ( $\mathrm{PRx} \geq 0.2)$ was equally distributed among changes in $\mathrm{P}_{\mathrm{bt}} \mathrm{O}_{2}\left(\mathrm{P}_{\mathrm{bt}} \mathrm{O}_{2}\right.$ drops: baseline $36 \%$, peak $35 \%$; $\mathrm{P}_{\mathrm{bt}} \mathrm{O}_{2}$ increases: baseline $36 \%$, peak $38 \%$ ).

Brain tissue hypoxia at baseline of effervescence was evident in $19 \%$ of episodes $(38 / 202)$. When analyzing only these episodes, overall $\mathrm{P}_{\mathrm{bt}} \mathrm{O}_{2}$ improved $\left(\Delta \mathrm{P}_{\mathrm{bt}} \mathrm{O}_{2}+5.0 \pm 7.2 \mathrm{mmHg}\right.$, $p<0.001) . \mathrm{P}_{\mathrm{bt}} \mathrm{O}_{2}$ increased in $47 \%$, did not change in $45 \%$, and decreased in $8 \%$ of these episodes. $\mathrm{CPP}_{\text {baseline }}(p<0.001)$ and $\mathrm{CPP}_{\text {peak }}(p=0.001)$ levels were lower as compared with temperature increases with normal $\mathrm{P}_{\mathrm{bt}} \mathrm{O}_{2}$ levels at baseline (Table 3 ).

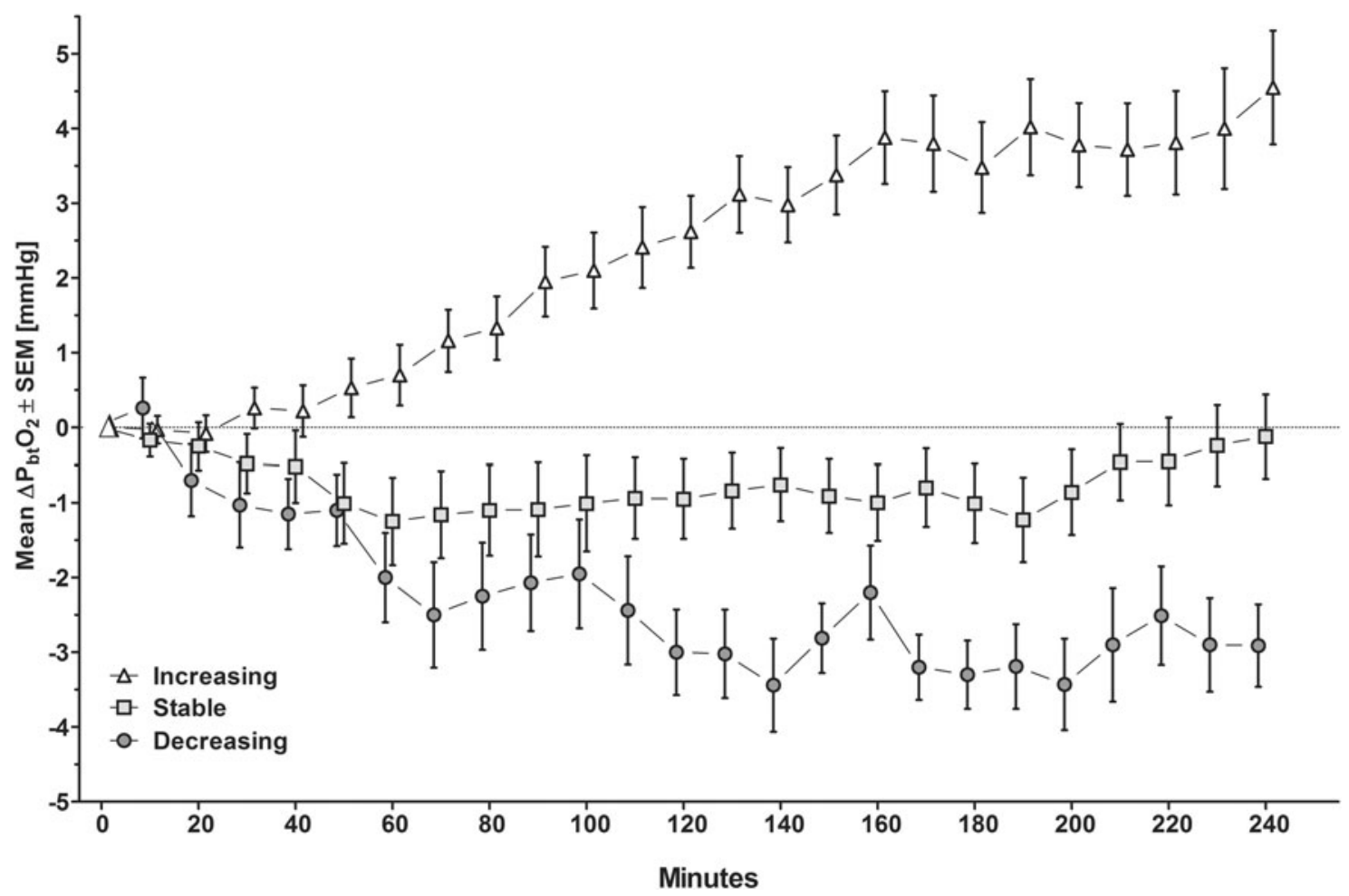

FIG. 2. Displays different mean $\mathrm{P}_{b t} \mathrm{O}_{2}$ changes during 202 episodes of temperature increases. $\mathrm{P}_{b t} \mathrm{O}_{2}$, brain tissue oxygen tension. SEM, standard error of the mean. 
Table 3. Changes in Brain Tissue Oxygen Tension and Hemodynamic Variables During Temperature Increases Splitting at Brain Tissue Oxygen Tension $<20$ mmHg and Brain Tissue Oxygen Tension $\geq 20$ MMHG AT BASELINE

\begin{tabular}{|c|c|c|c|c|c|c|c|c|c|c|c|c|}
\hline & $P_{b t} O_{2} b l$ & $P_{b t} O_{2}$ peak & $\Delta P_{b t} O_{2}$ & $T b l$ & $T$ peak & $\Delta T$ & $C P P b l$ & CPP peak & $\triangle C P P$ & $M A P b l$ & MAP peak & $\triangle M A P$ \\
\hline $\begin{array}{r}\mathrm{P}_{\mathrm{bt}} \mathrm{O}_{2} \text { baseline } \\
<20 \mathrm{mmHg}\end{array}$ & $12.3 \pm 5.2$ & $17.3 \pm 7.8$ & $5.0 \pm 7.2$ & $36.7 \pm 0.8$ & $37.8 \pm 0.7$ & $1.1 \pm$ & 3.9 & $09.1 \pm$ & 0.5 & 00. & $81.2 \pm$ & 1.0 \\
\hline$N=38$ & OR=1.13; & b-CI $=1.08$ & $19 ; p<0.001$ & & & & & $p=0$ & & & & \\
\hline $\begin{array}{r}\mathrm{P}_{\mathrm{bt}} \mathrm{O}_{2} \text { baseline } \\
>20 \mathrm{mmHg}\end{array}$ & $31.3 \pm 7.2$ & $31.2 \pm 8.9$ & $-0.1 \pm 5.5$ & $37.0 \pm 0.8$ & $37.9 \pm 0.7$ & $1.0 \pm 0.5$ & $82.7 \pm 16.5$ & $77.7 \pm 14.8$ & $-5.0 \pm 12.8$ & $98.1 \pm 17.9$ & $94.5 \pm 17.6$ & $-3.6 \pm 10.3$ \\
\hline$N=164$ & & $p=0.203$ & & & & & \multicolumn{3}{|c|}{$\mathrm{OR}=0.86 ; 95 \%-\mathrm{CI}=0.80-0.94 ; p=0.001$} & \multicolumn{3}{|c|}{$\mathrm{OR}=0.90 ; 95 \%-\mathrm{CI}=0.85-0.96 ; p=0.001$} \\
\hline
\end{tabular}

Hemodynamic and neuromonitoring parameters are expressed as mean \pm standard deviation at baseline and highest temperature within each episode

of temperature increase. Using generalized estimating equations, the significance of changes of each variables $(\Delta)$ within temperature increases

was tested in univariate analysis. Significant changes $(p<0.05)$ are bold.

bl, baseline; CI, confidence interval; CPP, cerebral perfusion pressure; HR, heart rate; ICP, intracerebral pressure; MAP, mean arterial

pressure; OR, odds ratio; ORx, oxygen reactivity index; $\mathrm{P}_{\mathrm{bt}} \mathrm{O}_{2}$, brain tissue oxygen tension; PRx, pressure reactivity index; $\mathrm{T}$, temperature.

Splitting temperature increases by baseline temperature $\left(<37.5^{\circ} \mathrm{C} ; 75 \%\right.$ and $\left.\geq 37.5^{\circ} \mathrm{C} ; 25 \%\right)$, analysis revealed significant increases in $\mathrm{P}_{\mathrm{bt}} \mathrm{O}_{2}$ only when baseline temperature was normothermic $(p=0.014)$. Further details are given in Table 4.

\section{Manually versus parametric detection of temperature increases}

Assisted episode detection of temperature increases revealed (1) 71 (total increase of $\geq 0.5^{\circ} \mathrm{C}$ ), (2) 183 (increase lasting $\geq 1 \mathrm{~h}$ ), and (3) 532 (increase lasting $\geq 20$ minutes) episodes when applying the algorithm as described in the Methods section. Again, $\mathrm{P}_{\mathrm{bt}} \mathrm{O}_{2}$ more often increased (method 1: $51 \%, 2: 58 \%, 3: 53 \%$ ). Analysis of hemodynamic variables during algorithm-supported detection of temperature increases yielded similar results as compared with visually identified temperature increases (Supplementary Table S1 and Supplementary Fig. S2).

\section{Discussion}

The main finding of the current study is that variable changes in $\mathrm{P}_{b t} \mathrm{O}_{2}$ can be observed when temperature increases in severe TBI patients. $\mathrm{P}_{\mathrm{bt}} \mathrm{O}_{2}$ increased on average in every third episode and decreased in every sixth episode. Importantly, a drop in $\mathrm{P}_{b t} \mathrm{O}_{2}$ occurred simultaneously to a decrease in CPP in the context of a decrease in MAP. Although more episodes of temperature increases were identified by visual curve inspection, algorithm-supported detection was feasible and revealed similar hemodynamic changes.
In the overall cohort, we found a weak-positive correlation between absolute temperature and $\mathrm{P}_{\mathrm{bt}} \mathrm{O}_{2}$ levels, which is consistent with previous reports (Spiotta et al., 2008; Nyholm et al., 2017). To the best of our knowledge, this is the first study analyzing time-coded dynamic systemic changes and brain oxygenation during episodes of temperature increases at different baseline temperature levels. Our study suggests that alterations of temperature may negatively affect brain hemodynamics only in a minority of analyzed episodes. In a recent prospective observational study in TBI patients, brain temperature variations $\left(>1^{\circ} \mathrm{C}\right)$ were associated with poor functional outcome (Weng et al., 2019). Similarly, a higher temperature variability within the first 48 hours was associated with poor functional outcome in the control group treated with normothermia in a post hoc analysis of the EUROTHERM trial (Abu-Arafeh et al., 2018). It is important to mention that a higher temperature variation may simply reflect a higher treatment intensity of fever, which is more common in patients with more severe brain injury. In the current study, we aimed to study pathophysiological changes associated with temperature increases. Temperature decreases reflecting treatment episodes of fever were excluded because of the potential side effects of pharmacological interventions on systemic and cerebral hemodynamics (Ianosi et al., 2019). Based on the observed temperature increase per hour, the etiology of fever episodes in our study most likely represents either infectious or neurogenic fever and not physiologic circadian changes in body temperature.

In our cohort, the overall impact of temperature changes on brain tissue oxygen tension was minute. During most effervescence episodes, $\mathrm{P}_{\mathrm{bt}} \mathrm{O}_{2}$ increased or remained stable, which

Table 4. Changes in Brain Tissue Oxygen Tension and Hemodynamic Variables During Temperature Increases SplitTing at Temperature $<37.5^{\circ} \mathrm{C}$ And Temperature $\geq 37.5^{\circ} \mathrm{C}$ At Baseline

\begin{tabular}{|c|c|c|c|c|c|c|c|c|c|c|c|c|}
\hline & $P_{b t} O_{2} b l$ & $P_{b t} O_{2}$ peak & $\Delta P_{b t} O$ & $T b l$ & $T$ peak & $\Delta T$ & $C P P b l$ & CPP peak & $\triangle C P P$ & $M A P b l$ & MAP peak & $\triangle M A P$ \\
\hline $\begin{array}{l}\mathrm{T} \text { baseline } \\
<37.5^{\circ} \mathrm{C}\end{array}$ & $27.5 \pm 10.9$ & $28.8 \pm 11.0$ & $1.2 \pm 6.7$ & $36.6 \pm 0.7$ & $37.7 \pm 0.6$ & $1.1 \pm 0.6$ & $79.5 \pm 17.2$ & $74.2 \pm 15.3$ & $-5.3 \pm 12.6$ & $94.5 \pm 18.6$ & $90.7 \pm 17.1$ & $-3.7 \pm 10.5$ \\
\hline$N=152$ & $\mathrm{OR}=1.04 ; 95$ & $\%-\mathrm{CI}=1.01-$ & $08 ; p=0.014$ & & & & $\mathrm{OR}=0.89 ; 95$ & $\%-\mathrm{CI}=0.82$ & $.96 ; p=0.003$ & $\mathrm{OR}=0.93 ; 95$ & $\%-\mathrm{CI}=0.87-0$ & $.99 ; p=0.013$ \\
\hline $\begin{array}{l}\mathrm{T} \geq 37.5^{\circ} \mathrm{C} \\
N=50\end{array}$ & $28.2 \pm 7.5$ & $\begin{array}{l}28.0 \pm 7.5 \\
p=0.730\end{array}$ & $-0.2 \pm 3.6$ & $37.8 \pm 0.3$ & $38.6 \pm 0.3$ & $0.7 \pm 0.2$ & $82.0 \pm 15.7$ & $\begin{array}{c}81.6 \pm 12.3 \\
p=0.366\end{array}$ & $-0.4 \pm 12.2$ & $100.0 \pm 13.3$ & $\begin{array}{c}100.4 \pm 15.5 \\
p=0.404\end{array}$ & $0.4 \pm 9.8$ \\
\hline
\end{tabular}

Hemodynamic and neuromonitoring parameters are expressed as mean \pm standard deviation at baseline and highest temperature within each episode

of temperature increase. Using generalized estimating equations, the significance of changes of each variables $(\Delta)$ within temperature increases was tested in univariate analysis. Significant changes $(p<0.05)$ are bold.

bl, baseline; CI, confidence interval; CPP, cerebral perfusion pressure; HR, heart rate; ICP, intracerebral pressure; MAP, mean arterial pressure; OR, odds ratio; ORx, oxygen reactivity index; $\mathrm{P}_{\mathrm{bt}} \mathrm{O}_{2}$, brain tissue oxygen tension; $\mathrm{PRx}$, pressure reactivity index; $\mathrm{T}$, temperature. 
TABle 3. (CONTINUED)

\begin{tabular}{|c|c|c|c|c|c|c|c|c|c|c|c|}
\hline$I C P b l$ & ICP peak & $\triangle I C P$ & $H R b l$ & $H R$ peak & $\Delta H R$ & $P R x b l$ & PRx peak & $\triangle P R x$ & $O R x b l$ & ORx peak & $\Delta O R x$ \\
\hline $16.7 \pm 10.7$ & $18.1 \pm 13.2$ & $1.3 \pm 6.6$ & $72.2 \pm 16.5$ & $75.6 \pm 19.5$ & $3.4 \pm 10.7$ & $0.23 \pm 0.34$ & $0.07 \pm 0.38$ & $-0.16 \pm 0.37$ & $0.34 \pm 0.36$ & $0.26 \pm 0.38$ & $-0.15 \pm 0.48$ \\
\hline $15.4 \pm 11.8$ & $\begin{array}{l}p=0.767 \\
17.1 \pm 12.6\end{array}$ & $1.8 \pm 10.3$ & $76.5 \pm 17.2$ & $\begin{array}{l}p=0.161 \\
82.1 \pm 16.7\end{array}$ & $5.6 \pm 9.3$ & $0.09 \pm 0.33$ & $\begin{array}{r}p=0.589 \\
0.14 \pm 0.37\end{array}$ & $0.06 \pm 0.38$ & $\begin{array}{c}\mathbf{O R}=\mathbf{0 . 9 9 7 ;} \mathbf{9} \\
0.21 \pm 0.36\end{array}$ & $\begin{array}{c}\boldsymbol{\%}-\mathbf{C I}=\mathbf{0 . 9 9 5} \\
0.25 \pm 0.35\end{array}$ & $\begin{aligned}-\mathbf{1 . 0 0} ; \boldsymbol{p} & =\mathbf{0 . 0 3 1} \\
0.05 & \pm 0.40\end{aligned}$ \\
\hline \multicolumn{3}{|c|}{$\mathrm{OR}=1.07 ; 95 \%-\mathrm{CI}=1.00-1.13 ; p=0.044$} & \multicolumn{3}{|c|}{$\mathrm{OR}=1.15 ; 95 \%-\mathrm{CI}=1.09-1.21 ; p<0.001$} & & $p=0.357$ & & \multicolumn{3}{|c|}{$p=0.717$} \\
\hline
\end{tabular}

is in line with previous data (Stocchetti et al., 2005). This observation was independent of baseline temperature and baseline $\mathrm{P}_{\mathrm{bt}} \mathrm{O}_{2}$. It is important to keep in mind that the measured $\mathrm{P}_{\mathrm{bt}} \mathrm{O}_{2}$ levels reflect the balance between oxygen delivery, consumption, tissue diffusion, and extraction (Rosenthal et al., 2008). Therefore, the shift of the oxygen dissociation curve in hyperthermic conditions with a higher oxygen extraction may serve as one explanation for the observed overall increase of $\mathrm{P}_{\mathrm{bt}} \mathrm{O}_{2}$ during effervescence (Siggaard-Andersen et al., 1984). Moreover, normal or even increasing $\mathrm{P}_{\mathrm{bt}} \mathrm{O}_{2}$ levels during temperature increases in our study suggest that the extended metabolic demand was met by upregulated energy supply (Rossi et al., 2001; Stocchetti et al., 2005). This is important and may separate pathophysiological changes observed during effervescences in TBI patients from other stroke patients, where fever exacerbates ischemic injury (Busto et al., 1987). In case of metabolic coupling, regional cerebral blood flow $(\mathrm{CBF})$ increases in parallel to $\mathrm{P}_{\mathrm{bt}} \mathrm{O}_{2}$ through vasodilation (Jaeger et al., 2005), which bears the risk of raised ICP (Stocchetti et al., 2005). In our patients, ICP was well controlled and changes in ICP $(\triangle \mathrm{ICP} 0.6 \mathrm{mmHg})$ were negligible, irrespective of the baseline autoregulatory status as expressed by PRx (data not shown). Other cardiovascular effects of temperature increases include a higher cardiac output, which may augment oxygen delivery (Bain et al., 2014; Walter et al., 2016). Another explanation, why $\mathrm{P}_{b t} \mathrm{O}_{2}$ increased in most of episodes is that cerebral autoregulation was preserved during the majority of episodes.

In a smaller proportion of episodes, we observed drops in $\mathrm{P}_{\mathrm{bt}} \mathrm{O}_{2}$ levels. This is of interest as previous studies report on the overall effect of temperature increases on $\mathrm{P}_{b t} \mathrm{O}_{2}$ and did not include the longitudinal information of $\mathrm{P}_{\mathrm{bt}} \mathrm{O}_{2}$ patterns (Stocchetti et al., 2005). The most likely explanation for $\mathrm{P}_{\mathrm{bt}} \mathrm{O}_{2}$ drops is the observed decrease in CPP secondary to a decrease in MAP. It is well known that hypotension may occur during fever as a consequence of vasodilation and redistribution of blood (Bain et al., 2014; Walter et al., 2016). It is important to mention that most of the centers applied a $\mathrm{P}_{b_{t}} \mathrm{O}_{2}$-guided treatment concept aiming at the prevention of brain tissue hypoxia. Although, mean baseline $\mathrm{P}_{\mathrm{bt}} \mathrm{O}_{2}$ was mostly above $20 \mathrm{mmHg}$, new brain tissue hypoxia was commonly observed during episodes when $\mathrm{P}_{\mathrm{bt}} \mathrm{O}_{2}$ decreased (30\%). In the overall cohort, brain tissue hypoxia developed on average in every sixth episode and persisted in every tenth episode reflecting a considerable risk of secondary brain injury during effervescences. We may have underestimated the incidence of brain tissue hypoxia in our cohort, based on the assumption that low $\mathrm{P}_{\mathrm{bt}} \mathrm{O}_{2}$ was treated in most centers. In the current understanding, continuous monitoring of $\mathrm{P}_{\mathrm{bt}} \mathrm{O}_{2}, \mathrm{CPP}$, and blood pressure may help to minimize the risk of brain tissue hypoxia. Although a hyperventilatory response to pyrexia is common and may lead to a reduction in $\mathrm{CBF}$ and $\mathrm{P}_{\mathrm{bt}} \mathrm{O}_{2}$ by respiratory alkalosis (Bain et al., 2014), this well-established effect may be negligible in this patient population, where a controlled mechanical ventilation was applied.

Notably, different patterns of $\mathrm{P}_{\mathrm{bt}} \mathrm{O}_{2}$ changes were observed in the same patient, suggesting that the association between temperature increases and $\mathrm{P}_{\mathrm{bt}} \mathrm{O}_{2}$ may depend on many factors, including the phase of disease, baseline vasopressor need, and the status of cerebral autoregulation.

In the current study, we aimed to identify increases in temperature by manual and algorithm-supported detection.

TABLE 4. (CONTINUED)

\begin{tabular}{|c|c|c|c|c|c|c|c|c|c|c|c|}
\hline$I C P b l$ & ICP peak & $\triangle I C P$ & $H R b l$ & HR peak & $\Delta H R$ & PRx ble & PRx peak & $\triangle P R x$ & $O R x b l$ & ORx peak & $\Delta O R x$ \\
\hline $14.9 \pm 10.1$ & $16.8 \pm 12.7$ & $2.0 \pm 9.1$ & $73.8 \pm 17.0$ & $78.9 \pm 17.5$ & $5.2 \pm 10.0$ & $0.10 \pm 0.34$ & $0.11 \pm 0.38$ & $0.01 \pm 0.38$ & $0.21 \pm 0.36$ & $0.26 \pm 0.36$ & $0.04 \pm 0.44$ \\
\hline $\begin{array}{c}\mathbf{O R}=\mathbf{1 . 0 7} ; \mathbf{9} \\
18.0 \pm 14.9\end{array}$ & $\begin{array}{c}\mathbf{b}-\mathbf{C I}=\mathbf{1 . 0 1}- \\
18.8 \pm 12.6 \\
p=0.943\end{array}$ & $\begin{array}{c}12 ; \boldsymbol{p}=\mathbf{0 . 0 1 2} \\
0.8 \pm 11.3\end{array}$ & $\begin{array}{c}\text { OR }=1.11 ; 95 \\
81.7 \pm 16.4 \\
\text { OR=1.21; } 95\end{array}$ & $\begin{array}{c}6-\mathbf{C I}=\mathbf{1 . 0 6}-\mathbf{1} \\
86.7 \pm 15.9 \\
0-\mathbf{C I}=\mathbf{1 . 0 9 - 1}\end{array}$ & $\begin{array}{c}17 ; \boldsymbol{p}<\mathbf{0 . 0 0 1} \\
5.0 \pm 8.1 \\
34 ; \boldsymbol{p}<\mathbf{0 . 0 0 1}\end{array}$ & $0.15 \pm 0.31$ & $\begin{array}{c}p=0.332 \\
0.19 \pm 0.37 \\
p=0.332\end{array}$ & $0.04 \pm 0.41$ & $0.29 \pm 0.34$ & $\begin{array}{r}p=0.828 \\
0.24 \pm 0.34 \\
p=0.107\end{array}$ & $-0.06 \pm 0.33$ \\
\hline
\end{tabular}


Interestingly, we could identify more episodes through visual plot analysis because of the basic and strict regulations of the parametric method. To align the method to the "softer" human detection, a better preprocessing and methods with a less rigid rule set may help in the identification. Still, a software-based detection of effervescence is feasible, and the results of associated brain and systemic hemodynamic changes were similar. Moreover, advanced multivariable time-series methods could allow better identification of episodes. Future studies are needed to investigate whether a software-based method could be used at the patients' bedside to alarm the clinician even before a substantial temperature increase is reached. Such predictive models were feasible for predicting changes in ICP and $\mathrm{P}_{\mathrm{bt}} \mathrm{O}_{2}$ (Myers et al., 2016).

\section{Limitations}

Several limitations deserve consideration. We did not assess CBF and brain metabolic changes associated with effervescence, which leaves some interpretation of our results speculative. Second, time-coded vasopressor use was not recorded in our patients, which may have influenced the observed hemodynamic changes. Third, a $\mathrm{P}_{\mathrm{bt}} \mathrm{O}_{2}$-guided therapy targeting at normal $\mathrm{P}_{\mathrm{bt}} \mathrm{O}_{2}$ levels was applied in several centers, which makes our results not transferrable to centers without oxygen monitoring and without a comparable treatment approach. Still, the risk of brain tissue hypoxia may be likely higher without monitoring. Fourth, to avoid a bias of hemodynamic side effects of pharmacologic fever treatment, we did not include episodes of temperature decreases in our study. Moreover, fever management varies between European centers (Picetti et al., 2019) and may have made the interpretation of decreases in temperature challenging. Fifth, probe location of $\mathrm{P}_{\mathrm{bt}} \mathrm{O}_{2}$ catheters was not integrated in the current analysis. Since we investigated relative changes, probe location might not be of high importance. Moreover, the observation that different $\mathrm{P}_{\mathrm{bt}} \mathrm{O}_{2}$ patterns during temperature increase occurred within the same patients might further justify our approach. Sixth, the site to measure temperature differed among patients. It is well known that intracranial temperature may exceed body temperature by several degree Celsius in acute brain injury highlighting the difficulty of fever definition (McIlvoy, 2004). Since our analysis focused on temperature increases irrespective of fever, this definition was of minor importance. Next, a considerable number of patients with neuromonitoring had no simultaneous recordings of temperature and $\mathrm{P}_{\mathrm{bt}} \mathrm{O}_{2}$ and had to be excluded, which constitutes the risk of a selection bias. However, baseline characteristics and temperature levels did not differ among the groups. Last, following the GayLussac's Law, the pressure of oxygen rises in parallel with the temperature increases. This phenomenon could have influenced our results, as we are not aware in which patients combined $\mathrm{P}_{\mathrm{bt}} \mathrm{O}_{2}$ /temperature probes with automatic correction of $\mathrm{P}_{\mathrm{bt}} \mathrm{O}_{2}$ for patients' temperatures were used or whether temperature levels were manually entered in the remaining patients.

\section{Conclusion}

In summary, our study indicates that adequate brain tissue oxygen tension was preserved during most episodes of effervescences in patients with severe TBI. However, there was a considerable risk of brain tissue hypoxia during efferves- cences. On average in every sixth episode a decrease of brain tissue oxygen tension was observed simultaneous to a decrease in CPP, which supports the idea of continuous (neuro)monitoring in severe TBI patients.

\section{Animal or Human Experimentation}

The CENTER-TBI study (EC grant 602150) has been conducted in accordance with all relevant laws of the EU if directly applicable or of direct effect and all relevant laws of the country, where the recruiting sites were located, including but not limited to, the relevant privacy and data protection laws and regulations (the "Privacy Law"), the relevant laws and regulations on the use of human materials, and all relevant guidance relating to clinical studies from time to time in force including, but not limited to, the ICH Harmonized Tripartite Guideline for Good Clinical Practice (CPMP/ICH/135/95; "ICH GCP”) and the World Medical Association Declaration of Helsinki entitled "Ethical Principles for Medical Research Involving Human Subjects." Informed Consent by the patients and/or the legal representative/next of kin was obtained, accordingly to the local legislations, for all patients recruited in the Core Dataset of CENTER-TBI and documented in the e-CRF. Ethics approval was obtained for each recruiting site. The list of sites, Ethics Committees, approval numbers, and approval dates can be found on the website.

\section{Acknowledgments}

CENTER-TBI High-Resolution Substudy Participants and Investigators: Audny Anke: Department of Physical Medicine and Rehabilitation, University Hospital Northern Norway, Troms $\varnothing$, Norway; Bo-Michael Bellander: Department of Neurosurgery \& Anesthesia \& intensive care medicine, Karolinska University Hospital, Stockholm, Sweden; Erta Beqiri: NeuroIntensive Care, Niguarda Hospital, Milan, Italy; Andras Buki: Department of Neurosurgery, Medical School, University of Pécs, Hungary and Neurotrauma Research Group, János Szentágothai Research Center, University of Pécs, Hungary; Manuel Cabeleira: Brain Physics Laboratory, Division of Neurosurgery, Department of Clinical Neurosciences, University of Cambridge, Addenbrooke's Hospital, Cambridge, United Kingdom; Marco Carbonara: Neuro ICU, Fondazione IRCCS Cà Granda Ospedale Maggiore Policlinico, Milan, Italy; Arturo Chieregato: NeuroIntensive Care, Niguarda Hospital, Milan, Italy; Giuseppe Citerio: NeuroIntensive Care Unit, Department of Anesthesia \& Intensive Care, ASST di Monza, Monza, Italy; School of Medicine and Surgery, Università Milano Bicocca, Milano, Italy; Hans Clusmann: Department of Neurosurgery, Medical Faculty RWTH Aachen University, Aachen, Germany; Endre Czeiter: Department of Neurosurgery, University of Pecs and MTA-PTE Clinical Neuroscience MR Research Group and Janos Szentagothai Research Center, University of Pecs, Hungarian Brain Research Program (Grant No. KTIA 13 NAP-A-II/8), Pecs, Hungary; Marek Czosnyka: Brain Physics Laboratory, Division of Neurosurgery, Department of Clinical Neurosciences, University of Cambridge, Addenbrooke's Hospital, Cambridge, United Kingdom; Bart Depreitere: Department of Neurosurgery, University Hospitals Leuven, Leuven, Belgium; Ari Ercole: 
Division of Anesthesia, University of Cambridge, Addenbrooke's Hospital, Cambridge, United Kingdom; Shirin Frisvold: Department of Anesthesiology and Intensive Care, University Hospital Northern Norway, Tromso, Norway; Stefan Jankowski: Neurointensive Care, Sheffield Teaching Hospitals NHS Foundation Trust, Sheffield, United Kingdom; Danile Kondziella: Departments of Neurology, Clinical Neurophysiology and Neuroanesthesiology, Region Hovedstaden Rigshospitalet, Copenhagen, Denmark; Lars-Owe Koskinen: Department of Clinical Neuroscience, Neurosurgery, Umeå University, Umeå, Sweden; Ana Kowark: Department of Anesthesiology, University Hospital of Aachen, Aachen, Germany; David K. Menon: Division of Anesthesia, University of Cambridge, Addenbrooke's Hospital, Cambridge, United Kingdom; Geert Meyfroidt: Intensive Care Medicine, University Hospitals Leuven, Leuven, Belgium; Kirsten Moeller: Department Neuroanesthesiology, Region Hovedstaden Rigshospitalet, Copenhagen, Denmark; David Nelson: Department of Neurosurgery \& Anesthesia \& Intensive Care Medicine, Karolinska University Hospital, Stockholm, Sweden; Anna Piippo-Karjalainen: Helsinki University Central Hospital, Helsinki, Finland; Andreea Radoi: Department of Neurosurgery, Vall d'Hebron University Hospital, Barcelona, Spain; Arminas Ragauskas: Department of Neurosurgery, Kaunas University of Technology and Vilnius University, Vilnius, Lithuania; Rahul Raj: Helsinki University Central Hospital, Helsinki, Finland; Jonathan Rhodes: Department of Anesthesia, Critical Care \& Pain Medicine NHS Lothian \& University of Edinburg, Edinburgh, United Kingdom; Saulius Rocka: Department of Neurosurgery, Kaunas University of Technology and Vilnius University, Vilnius, Lithuania; Rolf Rossaint: Department of Anesthesiology, University Hospital of Aachen, Aachen, Germany; Juan Sahuquillo: Department of Neurosurgery, Vall d'Hebron University Hospital, Barcelona, Spain; Oliver Sakowitz: Klinik für Neurochirurgie, Klinikum Ludwigsburg, Ludwigsburg, Germany; Department of Neurosurgery, University Hospital Heidelberg, Heidelberg, Germany; Nina Sundström: Department of Radiation Sciences, Biomedical Engineering, Umea University, Umea, Sweden; Riikka Takala: Perioperative Services, Intensive Care Medicine, and Pain Management, Turku University Central Hospital and University of Turku, Turku, Finland; Tomas Tamosuitis: Neurointensive Care Unit, Kaunas University of Health Sciences, Kaunas, Lithuania; Olli Tenovuo: Rehabilitation and Brain Trauma, Turku University Central Hospital and University of Turku, Turku, Finland; Peter Vajkoczy: Neurologie, Neurochirurgie und Psychiatrie, CharitéUniversitätsmedizin Berlin, Berlin, Germany; Alessia Vargiolu: Neurointensive Care Unit, Department of Anesthesia \& Intensive Care, ASST di Monza, Monza, Italy; Rimantas Vilcinis: Department of Neurosurgery, Kaunas University of Health Sciences, Kaunas, Lithuania; Stefan Wolf: Department of Neurosurgery, Charité-Universitätsmedizin Berlin, corporate member of Freie Universität Berlin, Humboldt-Universität zu Berlin, and Berlin Institute of Health, Berlin, Germany; Alexander Younsi: Department of Neurosurgery, University Hospital Heidelberg, Heidelberg, Germany; Frederick A. Zeiler: Division of Anesthesia, University of Cambridge, Addenbrooke's Hospital, Cambridge, United Kingdom; Section of Neurosurgery, Department of Surgery, Rady Faculty of Health Sciences, University of Manitoba, Winnipeg, MB, Canada.

\section{Author Disclosure Statement}

No competing financial interests exist.

\section{Funding Information}

Data used in preparation of this article were obtained in the context of CENTER-TBI, a large collaborative project with the support of the European Union 7th Framework program (EC grant 602150). Additional funding was obtained from the Hannelore Kohl Stiftung (Germany), from OneMind (United States), and from Integra LifeSciences Corporation (United States).

\section{Supplementary Material}

Supplementary Table S1

Supplementary Figure S1

Supplementary Figure S2

\section{References}

Abu-Arafeh A, Rodriguez A, Paterson RL, et al. Temperature variability in a modern targeted temperature management trial. Crit Care Med 2018;46:223-228.

Bain AR, Morrison SA, Ainslie PN. Cerebral oxygenation and hyperthermia. Front Physiol 2014;5:92.

Busija DW, Leffler CW, Pourcyrous M. Hyperthermia increases cerebral metabolic rate and blood flow in neonatal pigs. Am J Physiol 1988;255:H343-H346.

Busto R, Dietrich WD, Globus MY, et al. Small differences in intraischemic brain temperature critically determine the extent of ischemic neuronal injury. J Cereb Blood Flow Metab 1987;7:729-738.

Carney N, Totten AM, O'Reilly C, et al. Guidelines for the management of severe traumatic brain injury, fourth edition. Neurosurgery 2017;80:6-15.

Comtois D. Summarytools: Tools to Quickly and Neatly Summarize Data, R package version 0.9.4. 2019.

Czosnyka M, Smielewski P, Kirkpatrick P, et al. Continuous assessment of the cerebral vasomotor reactivity in head injury. Neurosurgery 1997;41:11-17; discussion 17-19.

Flynn LM, Rhodes J, Andrews PJ. Therapeutic hypothermia reduces intracranial pressure and partial brain oxygen tension in patients with severe traumatic brain injury: preliminary data from the Eurotherm 3235 trial. Ther Hypothermia Temp Manag 2015;5:143-151.

Greer DM, Funk SE, Reaven NL, et al. Impact of fever on outcome in patients with stroke and neurologic injury: a comprehensive meta-analysis. Stroke 2008;39:3029-3035.

Holtzclaw BJ. The febrile response in critical care: state of the science. Heart Lung 1992;21:482-501.

Ianosi B, Rass V, Gaasch M, et al. An observational study on the use of intravenous non-opioid analgesics and antipyretics in poor-grade subarachnoid hemorrhage: effects on hemodynamics and systemic and brain temperature. Ther Hypothermia Temp Manag 2020;10:27-36.

Jaeger M, Schuhmann MU, Soehle M, et al. Continuous assessment of cerebrovascular autoregulation after traumatic brain injury using brain tissue oxygen pressure reactivity. Crit Care Med 2006;34:1783-1788.

Jaeger M, Soehle M, Schuhmann MU, et al. Correlation of continuously monitored regional cerebral blood flow and brain tissue oxygen. Acta Neurochir (Wien) 2005;147:51-56; discussion 56. 
Kilpatrick MM, Lowry DW, Firlik AD, et al. Hyperthermia in the neurosurgical intensive care unit. Neurosurgery 2000;47: 850-855; discussion 855-856.

Le Roux P, Menon DK, Citerio G, et al. Consensus summary statement of the International Multidisciplinary Consensus Conference on Multimodality Monitoring in Neurocritical Care: a statement for healthcare professionals from the Neurocritical Care Society and the European Society of Intensive Care Medicine. Neurocrit Care 2014;21(Suppl 2):S1-S26.

McIlvoy L. Comparison of brain temperature to core temperature: a review of the literature. J Neurosci Nurs 2004;36:23-31.

Myers RB, Lazaridis C, Jermaine CM, et al. Predicting intracranial pressure and brain tissue oxygen crises in patients with severe traumatic brain injury. Crit Care Med 2016;44: 1754-1761.

Nyholm L, Howells T, Lewen A, et al. The influence of hyperthermia on intracranial pressure, cerebral oximetry and cerebral metabolism in traumatic brain injury. Ups J Med Sci 2017;122:177-184.

Picetti E, Oddo M, Prisco L, et al. A survey on fever monitoring and management in patients with acute brain injury: the SUMMA study. J Neurosurg Anesthesiol 2019;31:399-405.

Rosenthal G, Hemphill JC, 3rd, Sorani M, et al. Brain tissue oxygen tension is more indicative of oxygen diffusion than oxygen delivery and metabolism in patients with traumatic brain injury. Crit Care Med 2008;36:1917-1924.

Rossi S, Zanier ER, Mauri I, et al. Brain temperature, body core temperature, and intracranial pressure in acute cerebral damage. J Neurol Neurosurg Psychiatry 2001;71:448-454.

Siggaard-Andersen $\mathrm{O}$, Wimberley $\mathrm{PD}$, Gothgen I, et al. A mathematical model of the hemoglobin-oxygen dissociation curve of human blood and of the oxygen partial pressure as a function of temperature. Clin Chem 1984;30:1646-1651.

Spiotta AM, Stiefel MF, Heuer GG, et al. Brain hyperthermia after traumatic brain injury does not reduce brain oxygen. Neurosurgery 2008;62:864-872; discussion 872.

Steyerberg EW, Wiegers E, Sewalt C, et al. Case-mix, care pathways, and outcomes in patients with traumatic brain in- jury in CENTER-TBI: a European prospective, multicentre, longitudinal, cohort study. Lancet Neurol 2019;18:923-934.

Stocchetti N, Protti A, Lattuada M, et al. Impact of pyrexia on neurochemistry and cerebral oxygenation after acute brain injury. J Neurol Neurosurg Psychiatry 2005;76:1135-1139.

Tokutomi T, Morimoto K, Miyagi T, et al. Optimal temperature for the management of severe traumatic brain injury: effect of hypothermia on intracranial pressure, systemic and intracranial hemodynamics, and metabolism. Neurosurgery 2003;52: 102-111; discussion 111-112.

Walter EJ, Hanna-Jumma S, Carraretto M, et al. The pathophysiological basis and consequences of fever. Crit Care 2016;20:200.

Wang $\mathrm{H}$, Wang B, Normoyle KP, et al. Brain temperature and its fundamental properties: a review for clinical neuroscientists. Front Neurosci 2014;8:307.

Weng WJ, Yang C, Huang XJ, et al. Effects of brain temperature on the outcome of patients with traumatic brain injury: a prospective observational study. J Neurotrauma 2019;36: 1168-1174.

Zeileis A, Grothendieck G. zoo: S3 infrastructure for regular and irregular time series. J Stat Softw 2005;14:27.

Zhi D, Zhang S, Lin X. Study on therapeutic mechanism and clinical effect of mild hypothermia in patients with severe head injury. Surg Neurol 2003;59:381-385.

Address correspondence to: Raimund Helbok, MD Department of Neurology Medical University of Innsbruck Anichstrasse 35 6020 Innsbruck Austria

E-mail: raimund.helbok@tirol-kliniken.at; raimund.helbok@i-med.ac.at 